ISSN 2071-1050

www.mdpi.com/journal/sustainability

Review

\title{
Benefits and Costs of Biologically Contained Genetically Modified Tomatoes and Eggplants in Italy and Spain
}

\section{Rolf A. Groeneveld ${ }^{1, *}$, Erik Ansink ${ }^{2}$, Clemens C.M. van de Wiel ${ }^{3}$ and Justus Wesseler ${ }^{4}$}

1 Wageningen University, Environmental Economics and Natural Resources Group, Hollandseweg 1, Wageningen $6706 \mathrm{KN}$, The Netherlands

2 VU University Amsterdam, Institute for Environmental Studies, De Boelelaan 1087, Amsterdam 1081 HV, The Netherlands; E-Mail: erikansink@gmail.com

3 WUR Plant Breeding, Droevendaalsesteeg 1, Wageningen 6708 PB, The Netherlands; E-Mail: clemens.vandewiel@wur.nl

4 Chair Group Agricultural and Food Economics, Center of Life and Food Sciences Weihenstephan, Technische Universität München, Weihenstephaner Steig 22, Freising 85354, Germany; E-Mail: justus.wesseler@wzw.tum.de

* Author to whom correspondence should be addressed; E-Mail: rolf.groeneveld@wur.nl; Tel.: +31-317-482009; Fax: +31-317-484933.

Received: 22 April 2011; in revised form: 22 June 2011 / Accepted: 12 August 2011 /

Published: 22 August 2011

\begin{abstract}
In this paper we assess the benefits and costs of introducing biologically contained genetically modified (GM) crops, with an application to the potential introduction of GM tomatoes and eggplants in Italy and Spain. Such crops possess both the standard beneficial GM traits, and they prevent introgression of transgenes from GM crops to their conventional or wild relatives, thereby adding to the safety of their cultivation. As a result, coexistence regulations for these crops are less stringent than for crops without biological containment. The potential adoption of biologically contained GM tomatoes and eggplants is assessed in a cost-benefit framework for Italy and Spain. We conclude that biological containment has considerable potential benefits if policy makers are willing to loosen the restrictions on the introduction of these varieties.
\end{abstract}

Keywords: tomato; eggplant; genetic modification; coexistence; biological containment; economics 


\section{Introduction}

Genetically modified (GM) crops can substantially reduce the environmental footprint of agriculture and increase the sustainability of agriculture production. The potential contribution of GM crops to improve sustainability of agriculture productions includes higher yields per unit of land, reduced pesticide and fuel use, positive effects on biological diversity and soil conservation resulting in an increase in ecosystem services [1,2]. There is a concern, however, that transgenes may be transferred to non-GM crops or even wild relatives. This gene flow can be inhibited by physical measures, such as isolation distances between GM crops and conventional varieties or wild relatives, and by biological containment, i.e., by introducing changes in the plant's reproductive systems preventing dispersal of viable seeds and/or outcrossing through pollen. An example of such a containment measure is the control of pollen-mediated gene flow from the plant via transgenic male-sterility systems $[3,4]$. Hence, biologically contained GM crops do not require the stringent coexistence regulation that exists for regular GM crops in the European Union and are under debate in the US [1,5].

In this paper we assess the benefits and costs of introducing biologically contained GM crops, with an application to the potential introduction of GM tomato (Solanum lycopersicum) and eggplant (Solanum melongena) in Italy and Spain. Such crops possess the standard beneficial GM traits that make them attractive for commercial cultivation. The prime example is $B t$ maize which has seen the widest adoption in Europe since it was first released in Spain in 1998 [6]. In addition to these beneficial traits, containment measures prevent movement of transgenes from GM crops to their conventional or wild relatives, thereby adding to the safety of the introduction of GM plants.

We assess the benefits and costs of biological containment in GM crops, based on the reduced coexistence compliance costs. In the paper we apply this to GM tomatoes and eggplants in Italy and Spain, but it is relevant to other GM crops that may be released for commercial cultivation in the EU. Calculation of the reduced coexistence compliance costs are based on a review of existing measures for GM crops in Italy and Spain, as well as a review of the technical aspects of GM tomatoes and eggplants that tells us which coexistence measures are relevant.

Existing studies show that the costs of coexistence measures for GM crops may be substantial [7,8]. A large and diverse portfolio of regulations exists to regulate the commercial cultivation of GM crops in Europe [1,5]. The costs associated with these measures, and minimum distance requirements in particular, can severely constrain the adoption of GM crops. Soregaroli and Wesseler [9] and Demont et al. [7,8] show that such regulations may disproportionally raise the costs of coexistence of GM with conventional crops, while Skevas et al. [10] show flexible coexistence regulations may allow farmers to reduce the coexistence compliance costs to almost zero. The benefit of cultivating biologically contained GM crops is evident. Compared with GM crops without biological containment, these crops require less stringent policies, or even no policies, to regulate their coexistence with both conventional and organic crops. Biologically contained GM crops thereby combine the benefits of standard GM crops with the benefits of avoided minimum distance requirement costs.

One may question the use of biological containment for coexistence of tomatoes and eggplants. Both are selfing crops with low probabilities for cross pollination. Nevertheless, the minimum distance requirements considered by EU member states for crops such as oil seed rape, maize and sugar beets 
often exceed what would be necessary from a scientific point of view [11]. One may even question the necessity for coexistence regulations from an economic point of view [12]. The pros and cons have been addressed by a number of authors [1,8,10,11,13-15]. As coexistence requirements are politically motivated, we hardly can expect cultivation of GM tomato and GM eggplants to be possible without coexistence regulations. Biological containment, when proven effective in practice, has the potential to result in less stringent coexistence regulations and it is worthwhile to investigate the amount of benefit to expect, while recognizing this may not necessarily convince decision makers.

Our results show that the potential short-run benefits (assuming infinite demand elasticities) of GM tomato and eggplant are significant. Minimum distance requirements will reduce such benefits and in particular the benefits to smaller vegetable farmers. Depending on the minimum distance requirements biological containment can provide substantial economic benefits and in particular for smaller farms.

The paper is organized as follows. In Section 2 we present the technical aspects of our analysis, focusing on GM traits and gene flow levels for GM tomatoes and eggplants. In Section 3 we present the relevant economic aspects, including both the benefits of these GM crops in terms of reduction of damage due to disease and other pressures, and the foregone costs of regulation in both Italy and Spain. In Section 4 we combine the results of our technical and economic review in a cost-benefit framework based on Beckmann and Wesseler [16], and we conclude in Section 5.

\section{The Technical Story: Traits and Cross-Pollination}

In this section we present the beneficial traits that can potentially be introduced through genetic modification into tomatoes and eggplants, as well as the species' risks of cross pollination.

\subsection{Traits}

The first commercially approved GM tomato was the so-called Flavr Savr, which had an increased shelf life and was sold in the US in the beginning of the 1990s. Though the commercial success was limited, many more traits of tomatoes and eggplants have been investigated since.

In the European Union, Italy and Spain have so far seen the largest number of field trials of GM tomatoes and eggplants (Table 1). The most important traits in these trials with tomato are resistance against viruses such as Cucumber Mosaic Virus (21 releases), Tomato Yellow Leaf Curl Virus (4 releases), Tomato Spotted Wilt Virus (one release) and Potato virus Y (one release). Other traits enhance the crop's quality, notably through parthenocarpy and extended shelf life. Lastly, herbicide tolerance and drought resistance have also been introduced into tomatoes. For eggplants, the most important traits under consideration are parthenocarpy and insect resistance through $B t$. 
Table 1. Deliberate releases in field trials of GM tomato and eggplant under Directives 90/220/EEC and 2001/18/EC.

\begin{tabular}{|c|c|c|c|c|c|c|c|}
\hline EU member state ${ }^{1}$ & FR & $\mathbf{E L}$ & IT & NL & PT & $\mathbf{E S}$ & $\mathbf{U K}$ \\
\hline \multicolumn{8}{|l|}{ Tomato } \\
\hline Quality & 2 & 1 & 11 & & 2 & 10 & 1 \\
\hline Parthenocarpy & 1 & & 5 & & & 2 & \\
\hline Virus & & & 26 & & & 3 & \\
\hline$B t$ & 2 & & 2 & & & & \\
\hline Fungi resistance & & & 1 & 2 & & & \\
\hline Herbicide tolerance & 3 & & 1 & & & & \\
\hline Other traits & & & 4 & & & 1 & \\
\hline Total & 5 & 2 & 49 & 2 & 2 & 16 & 1 \\
\hline \multicolumn{8}{|l|}{ Eggplant } \\
\hline$B t$ & & & 7 & & & & \\
\hline Parthenocarpy & & & 2 & & & & \\
\hline Total & & & 9 & & & & \\
\hline
\end{tabular}

Source: http://gmoinfo.jrc.ec.europa.eu/; ${ }^{1}$ FR: France; EL: Greece; IT: Italy; NL: The Netherlands; PT: Portugal; ES: Spain; and UK: United Kingdom.

\subsection{Cross-Pollination}

Tomato and eggplant are both selfing species, which suggests that there is only a small likelihood of gene flow by pollen. Plant species are very rarely completely selfing, however: cross-pollination enlarges genetic diversity within the species, which offers evolutionary advantages. Hence, some cross-pollination occurs in tomato and eggplant, albeit at a small percentage and depending on environmental conditions, typically in the range of $0-10 \%$ [17]. (The standard test to measure the adventitious presence of GM in non-GM crops is quantitative polymerase chain reaction (qPCR) [18]. As of now, however, it is uncertain how quantification of transgenes will be conducted for fruits like tomatoes and eggplants. The threshold level for labeling in the EU is $0.9 \%$, but the uncertainty is whether this percentage will be calculated over the whole fruit (i.e., both seeds and flesh) or only over the seeds - the only part of the tomato or eggplant where GM admixture can occur. Hence, the effective stringency of the $0.9 \%$ threshold varies on how the percentage transgene will be calculated, and therefore also the extent to which cross pollination will be more or less restrictive to the commercial success of GM tomato and eggplant.) Therefore, GM tomato and eggplant may affect wild relatives and non-GM relatives through cross-pollination.

Existing studies on transgene flow in tomatoes and eggplants show mixed results. For example, Ilardi and Barba [19] compared the frequency of spontaneous crossing of homozygous GM tomato (Lycopersicon esculentum) with that of a control group, and detected no GM pollen flow. In an open field trial, Accotto et al. [17] found that only $0.32 \%$ of the progeny of non-GM tomatoes near GM tomatoes contained transgenic DNA. These numbers varied according to pollinator activity as pollinating insects are more important than wind dispersal.

Early work by Sambandam [20] showed an average cross pollination rate of $6.75 \%$ for eggplant. Studies of eggplant in India have reported cross-pollination rates up to $20-48 \%$, mainly subject to the 
fruit's variety, geographical location, and insect activity [21]. Franceschetti and Lepori [22] find rates between $10 \%$ and $29 \%$. These cross-pollination rates are relatively high for a selfing species.

\section{The Economic Story: Benefits and Foregone Costs}

In this section we present the relevant economic aspects, including both the benefits of these GM crops in terms of reduction in damage from pathogens as well as possible increase in production, and the foregone costs of coexistence regulation in both Italy and Spain.

Current commercial cultivation of GM crops in Italy and Spain is very limited [6]. In Italy, there is no production yet of any GM crop. In Spain, commercial cultivation started in 1998 and now amounts to roughly 80,000 hectares of $B t$ maize, or $22 \%$ of total maize production in Spain [23]. When GM tomatoes or eggplants are introduced, there is a large potential cultivation area in both Italy and Spain, which are the top EU producers. In Italy, tomato production is $6,000,000 \mathrm{t}$ on 118,000 ha and eggplant production is $271,000 \mathrm{t}$ on $12,000 \mathrm{ha}$. In Spain, tomato production is 3,700,000 $\mathrm{t}$ on 54,000 ha and eggplant production is $185,000 \mathrm{t}$ on 4,250 ha for the year 2005 [24]. Other relatively large tomato and eggplant-producing countries in Europe include Greece (both tomato and eggplant), Portugal (tomato), and Romania (eggplant).

\subsection{Benefits of GM Traits}

\subsubsection{Tomato}

Agronomic properties of tomatoes can be improved with GM traits. One of these properties is reduced water deficit stress [25], which could allow cultivation on currently marginal land that meets tomato-production conditions in other respects. Conversely, it reduces the opportunity costs of growing tomato, as less water may be needed in the cultivation process.

Another property is virus resistance. This is a very relevant and potentially valuable trait for tomato cultivation. Martelli [26] mentions the example of Cucumber mosaic virus (CMV) and its necrogenic satellite RNA, and its destructive force to tomatoes. Lethal necrosis of tomato induced by CMV, a virus disease transmitted by aphids, recurs yearly in Mediterranean Europe over the last three decades. It has caused tomato farmers in several areas of southern Italy, where they were traditionally grown, to abolish the production of tomatoes altogether [26, 27].

Studies of the effect of virus resistance on productivity are often difficult to interpret. A complicating factor is often that pest infestation levels can be variable from year to year, therefore, yield advantages will also vary. Harvest security may then be the prime advantage of a pest-resistant GM crop. For instance, Accotto et al. [17] compare the occurrence of the Tomato spotted wilt virus (TSWV) in resistant GM tomatoes to that among non-resistant tomatoes in the absence of conventional treatment (TSWV infection can be reduced by the use of insecticides as it is transmitted by thrips). The authors find that the resistant GM tomatoes are not affected by TSWV whereas 33-50\% of non-resistant ones are. Tomassoli et al. [28] find that CMV-resistant tomatoes are commercially viable, although not as resistant to virus infections as found in the lab. Gianessi et al. [29] assess that Yellow Leaf Curl Virus (YLCV) resistance, a virus disease transmitted by white flies, may prevent a current yield loss of $1 \%$, and substitute for current prevention measures, which include insecticide use and netting. Yield 
losses can be much higher than that (even up to $100 \%$ [26]), but to stay on the conservative side we assume an average yield increase of $5 \%$.

In terms of yield per hectare, there are no large benefits of GM tomatoes. Herbicide tolerance offers no significant yield improvements [30], unless conventional weed control is suboptimal. Costs, however, are roughly $8.9 \%$ lower due to reduced herbicide use. Rotino et al. [31] find that parthenocarpic tomatoes bear slightly smaller fruits, but because the fruits are also more numerous the yields are comparable to non-parthenocarpic tomatoes.

A conservative monetary estimate of the benefits of GM tomatoes, based on the discussed traits and related benefits, can now be drawn. Virus resistance is likely to be the most important trait of GM tomatoes as the damages from virus epidemics are of a higher order of magnitude than, say, savings on herbicide use. Table 2 shows estimates of expenses on insecticides to control vectors in tomato production as found in the scientific literature. These figures suggest that these expenses may be anywhere between $€ 9$ and $€ 293$ per ha, although the majority of studies arrive at an estimate of about $€ 50$ or less. Not all insecticide use may be attributed to YLCV infection, but it gives at least an indication of the possible savings in insecticide use. If, as suggested by Gianessi et al. [29], YLCV resistance substitutes insecticide use, the monetary value of this trait may be in the same order of magnitude. For CMV resistance, however, the figures are less certain because neither insecticides nor transgenic resistance appear to be $100 \%$ effective $[28,29]$. Due to these complexities we disregard the possible savings in pesticide use of GM tomatoes.

Table 2. Costs of insecticide use $(€ /$ ha) in open-field tomato production according to different studies *).

\begin{tabular}{llll}
\hline Source & Area & Method & Insecticide \\
\hline Dartt et al. [32] & Michigan, USA & Focus group & $€ 34$ \\
Yardım and Edwards [33] & Ohio, USA & Field experiment & $€ 130$ \\
Tatlidil and Aktürk [34] & Çanakkale, Turkey & Farm survey & $€ 35-48^{* *}$ \\
Engindeniz [35] & Izmir, Turkey & Farm survey & $€ 106^{* *}$ \\
Esengun et al. [36] & Tokat, Turkey & Farm survey & $€ 293$ \\
Miyao et al. [37] & California, USA & Model study & $€ 9$ \\
Miyao et al. [38] & California, USA & Model study & $€ 11$ \\
\hline
\end{tabular}

* Costs in dollars were converted to euro's using real annual country exchange rates for the Eurozone from USDA (http://www.ers.usda.gov/Data/ExchangeRates/); ** Total costs of pesticide use.

Given the mentioned production levels of tomato of $51 \mathrm{t} / \mathrm{ha}$ in Italy and $68 \mathrm{t} / \mathrm{ha}$ in Spain, a $5 \%$ increase in yields at 2005 price levels, namely $€ 159$ per ton in Italy and $€ 522$ per ton in Spain [24] amounts to an increase in farm profit $€ 405$ per ha in Italy and $€ 1,775$ per ha in Spain.

In addition to these direct monetary effects, there are also non-pecuniary effects of GM traits that are harder to estimate. Marra and Piggott [39] estimate the value of non-pecuniary benefits of insect resistant corn at about US\$7 per ha, and about US\$12-24 for herbicide tolerant crops. We use the estimate for insect resistant corn as a proxy for non-pecuniary values for GM tomato and eggplant, as these values do not depend much on the type of crops under consideration. At 2005 real annual country exchange rates this amounts to about $€ 6$ per ha. 
Hence, calculated total benefits of GM tomato traits sum up to $€ 412$ per ha in Italy and $€ 1,781$ per ha in Spain. Costs of the technology are estimated at 34\% of the gains [40, 41], so that the calculated net gains amount to $€ 271$ per ha in Italy and $€ 1,175$ per ha in Spain.

\subsubsection{Eggplant}

Effects of GM in eggplant production mainly regards parthenocarpy and Bt. Parthenocarpic eggplants are found to be $25 \%$ more productive in winter cultivation, coinciding with a $10 \%$ reduction in cultivation costs, and in improved quality of the fruit [42]. Acciarri et al. [43] extend this analysis to spring and summer cultivation, both in greenhouse and open field conditions, and find a 30-35\% increase in productivity, mainly due to improved fruit-set under sub-optimal temperatures, combined with enhanced fruit growth and weight, and increased quality.

In addition to a positive effect on yield levels, $B t$ technology allows significant reductions in the application of insecticides. For instance, the gains from adoption of $B t$ eggplant in India would amount to about US\$108 million per year [44]. Another attractive trait is that GM eggplants may be endowed with nematode resistance [45], and other types of resistance that allow reducing the use of pesticides. Studies from India show that these reductions may amount up to $52 \%$ decreased pesticide use [44, 46]. Estimated impacts of $B t$ eggplant adoption in New Jersey includes a 22\% reduction insecticide use on eggplant [47].

A conservative monetary estimate of the benefits of GM eggplant, based on the discussed traits and related benefits, can now be drawn. The benefits to eggplant can be summarized as a productivity increase and reduced pesticide use. For the productivity increase an estimate of $25 \%$ seems reasonable $[42,43]$, and for reduced pesticide use we use the lowest estimate in the literature, which is $22 \%$ [47]. This survey provides us with the following crude parameter calculations.

Insecticide use in eggplant production is calculated at $€ 117$ per ha for oriental eggplant [48] and at $€ 723$ per ha for American eggplant [49] (converted from dollars to Euros using real country exchange rates with base year 2005 [50]). Gianessi et al. [47] suggest that insecticide use in eggplant production costs about $€ 193$ per ha, which $B t$ may reduce by $22 \%$, or $€ 42$ per ha. Given the mentioned production levels of eggplant of 23 ton per ha in Italy and 43 ton per ha in Spain, a 25\% increase in yields at 2005 price levels, namely $€ 413$ per ton in Italy and $€ 713$ per ton in Spain [24] amounts to an increase in farm profit of $€ 2,375$ per ha in Italy and $€ 7,665$ per ha in Spain. As is the case for GM tomato, these estimates are very high compared to the conventional increases in farm profits due to GM adoption. The calculated non-pecuniary effects of GM traits are, again taken from Marra and Piggott [39] and set at $€ 6$ per ha.

Hence, calculated total benefits of GM eggplant traits sum up to $€ 2,381$ per ha in Italy and $€ 7,671$ per ha in Spain. Costs of the technology are calculated at $34 \%$ of the gains [40], so that the calculated net gains amount to $€ 1,571$ per ha in Italy and $€ 5,063$ per ha in Spain.

\subsection{Foregone Costs of Coexistence Measures}

Regulations on coexistence of GM and non-GM crops in the EU are based on the general guidelines for coexistence developed by the European Commission [51]. There is a wide variety in the regulations that EU states have adopted to govern the production, processing, and sale of GM crops. Two types of 
regulation can be distinguished, ex ante and ex post, indicating the type of liability rules that farmers face in their decision to plant GM crops [5]. Ex ante regulation focuses on the conditions and constraints that farmers have to meet in the production process of GM crops. This type of regulation includes registration in specified databases, the duty to inform neighboring landowners, and requirements on a minimum distance between GM crops and their non-GM relatives. Ex post regulation focuses on the consequences (to the farmer) of the adventitious presence of GM crops in non-GM crops. This type of regulation includes the rules and requirements for damage compensation to non-GM farmers. These rules determine implicitly who has the burden of proof, the GM or the non-GM farmers.

In terms of these two types of regulation, the two countries of interest in this paper, Italy and Spain, have rather different regulation styles. Italy has relatively undeveloped national regulation, relying mostly on ex post liability rules. It has, however, decentralized the possibility for ex ante regulation to the regional level. Spain combines several ex ante measures with a more stringent and innovative ex post regulation. The relevant regulations are listed in Table 3.

Table 3. Relevant legislation on coexistence of GM and non-GM crops in Italy and Spain (Source: [1,5]).

\begin{tabular}{lll}
\hline Country & Type of regulation & Description \\
\hline Italy & Ex ante & Record keeping \\
& Expost & Burden of proof lies with GM farmer \\
\hline Spain & Ex ante & Registration of areas in publicly available database, \\
& & restricted access \\
& Record keeping \\
& Minimum distance requirements \\
& Buffer zones \\
& Expost & Liability based on civil law \\
& & Fines for non-compliance with ex ante regulations \\
\hline
\end{tabular}

In both countries, the approval of GM tomatoes or eggplants is expected to require a restrictive minimum distance requirement in order to avoid cross-pollination. The level of this distance requirement depends on the probability of cross-pollination and pollen dispersal distances. Recall that tomatoes and eggplants have both low levels of cross-pollination and small pollen dispersal distances, which would call for relatively low distances. The decision on minimum distance requirements, however, is largely a political decision, in which substantial safety margins are used in order to assure that no cross-pollination will occur. These safety margins differ considerably across EU member states. GM maize, for instance, has a minimum distance requirement ranging from $25 \mathrm{~m}$ in Sweden to $800 \mathrm{~m}$ in Luxembourg, although scientific evidence does not call for such distances larger than 15-50 m [14].

Two prominent alternative measures to regulate the coexistence of GM and non-GM crops are the use of buffer strips and the use of insect-proof nets. Buffer strips consist of a non-GM variety of the GM crop, planted in a strip along the outer border of the GM field. These strips are claimed to be more effective and more flexible than minimum distance requirements [8], although this claim is not uncontested [13]. Insect-proof nets can be used to isolate crops from the environment and thereby 
prevent transgene flow. This measure is only necessary during the flowering period, as isolation during this period is "one of the best methods to avoid hybridization" [52]. Accotto et al. [17] find that the use of nets is a very effective measure for GM tomato, reducing transgene flow to zero.

Despite the effectiveness of these two alternative measures, we find it unlikely that no minimum distance requirement will be imposed, given existing regulations and the political aspects related to the introduction of GM crops. In that respect, the situation for tomatoes and eggplants is similar to that of potato. Potato is a selfing crop with pollination rates comparable to those of eggplant (about 20\%). Distance measures for potato range from $2 \mathrm{~m}$ in Sweden to $50 \mathrm{~m}$ in Poland [23]. In this paper we assume a minimum distance of $50 \mathrm{~m}$ will be imposed.

A monetary assessment of the costs of minimum distance requirements very much depends on local management conditions. The following considerations are important: (1) the area currently and potentially under vegetable production; (2) the presence of non-GM vegetables of the same species within the minimum distance from the field's borders; (3) the parcellation of the farms; (4) the need for refuge areas in case of $B t$ eggplants, and the flexibility of regulations [10].

Besides the possible application of GM crops on existing agricultural land, some traits can open up areas to vegetable production that are currently unsuitable, for instance because of the prevalence of pests and diseases. This may particularly be the case for resistance to CMV, which has drastically reduced tomato production in Southern Italy [27].

A single non-GM field is able to trigger a so-called domino effect where adjacent fields are prevented from adopting GM crops, in turn preventing other fields from adopting, and so on [7]. Without spatially explicit information on farmers' readiness to adopt GM vegetables, however, it is difficult to say beforehand how many GM vegetable plots need to take distance measures.

The number of parcels of a farm, and the size and shape of those parcels matters because these factors determine what border length in the farm may lie close to a non-GM vegetable field. A farm with many parcels has longer borders per area unit than a similarly sized farm with fewer parcels. Moreover, smaller parcels or farms have longer borders per area unit, as well as more rectangular parcels.

The last consideration relates to cultivation practices and is best illustrated using the example of $B t$ eggplant. Bt eggplant has the unintended effect that resistance can be built up by the target insects. A management measure that mitigates this effect is the creation of refuge areas of conventional eggplant plants within a field of $B t$ eggplant. The requirement of a minimum distance would make it attractive to have these refuge areas on the outer edges of an eggplant plot. Hence, the regulation may possibly be easily incorporated in existing cultivation practices (e.g., [53-55]).

Given these considerations, the potential area of GM tomatoes or eggplants can theoretically be anything between zero and the current area of vegetable production, or even more. To gain at least a qualitative insight into the order of magnitude of the potential area of GM tomatoes and eggplants with and without biological containment, we make a number of simplifying assumptions.

As regards the area of vegetable production, we ignore the possibility that virus resistance increases the area of vegetable production. This likely leads to an underestimation of the potential area of GM vegetables, but it allows us to use current data on vegetable production in Italy and Spain.

As regards the minimum distance, we assume all fields with GM crops must have buffers of $50 \mathrm{~m}$ between the plot border and the GM crops. The buffer region of, say, a GM eggplant field can be used for non-GM eggplants that can serve as a refuge to prevent the build-up of Bt resistance. Crops from a 
buffer strip do not have the same benefits as GM crops, although they will probably have to be sold and processed as GM crops. This assumption also likely leads to an underestimation of the potential area of GM vegetables, because such buffer strips may not be necessary in many cases. For instance, there may be no non-GM vegetables of the same species around.

As regards parcellation, we assume all farms consist of a single square-shaped parcel. Parcels come in many shapes, although circular shapes may not be common. Field shape may influence the amount of pollen-mediated gene flow. Two rectangular fields have a larger border for exchange of pollen if they share a long border than if they share a short border. Moreover, rectangular plots have a lower amount of competing pollen around them as the area around the border is smaller, thereby preventing pollen influx from the other field [56]. To be on the safe side we base our calculations on square fields. Given these assumptions, a farm with area $A$ has four borders of length $a$. A required buffer of size $b$ the reduces the potential area of GM vegetables on this farm to

$$
B=\left(A^{1 / 2}-2 b\right)^{2}
$$

Table 4 shows the area of open field and market gardening vegetable production on farms of different size classes in Italy and Spain, as well as the number of enterprises involved. From these data we calculate $A$ for each size class and type of production by calculating the average vegetable production area per farm. Using Equation (1), we calculate the potential area of GM vegetables in each size class (labeled "GM" in Table 4). As explained above, these calculations are subject to very strong assumptions that may cause an upward as well as a downward bias. Nevertheless, the calculations give useful insight into the potential area of GM vegetables in Italy and Spain. The numbers indicate that under these assumptions about $79 \%$ and $66 \%$ of vegetable production land will be needed for coexistence buffers in Italy and Spain, respectively. The difference between the two countries stems from the fact that Italy has a larger proportion of small vegetable producers, which have a higher border-area ratio and hence a stronger impact of coexistence buffers. These numbers are considerably larger than the estimate of Gianessi et al. [29] that GM tomato varieties may be planted on about 53\% of tomato production area in Greece, Portugal, Italy and Spain.

Table 4. Average vegetable production area per farm in different farm size categories in Italy and Spain, and estimated net area available for GM vegetables under a buffer of $50 \mathrm{~m}$ from the parcel border.

\begin{tabular}{|c|c|c|c|c|c|c|c|c|c|}
\hline Farm size & $<1$ & $1-2$ & $2-5$ & 5-10 & $10-20$ & 20-30 & $30-50$ & 50-100 & $\geq 100$ \\
\hline \multicolumn{10}{|l|}{ Spain } \\
\hline \multicolumn{10}{|l|}{ Open field } \\
\hline No. & 2483 & 7144 & 7450 & 5465 & 3747 & 1877 & 2540 & 1934 & 1834 \\
\hline Area & 533 & 2469 & 5639 & 5775 & 7621 & 5777 & 7466 & 15,605 & 45,458 \\
\hline GM & 0 & 0 & 0 & 4 & 680 & 1,068 & 1,297 & 6,552 & 29,031 \\
\hline \multicolumn{10}{|c|}{ Market gardening } \\
\hline No. & 7900 & 12,512 & 18,576 & 14,123 & 11,255 & 5225 & 4126 & 3686 & 2290 \\
\hline Area & 2165 & 4407 & 10,889 & 10,947 & 15,921 & 12,767 & 13,062 & 25,883 & 46,212 \\
\hline GM & 0 & 0 & 0 & 0 & 404 & 1657 & 2506 & 10,034 & 27,928 \\
\hline GM total & 0 & 0 & 0 & 4 & 1084 & 2725 & 3802 & 16,586 & 56,958 \\
\hline
\end{tabular}


Table 4. Cont.

\begin{tabular}{llllllllll}
\hline Farm size & $<\mathbf{1}$ & $\mathbf{1 - 2}$ & $\mathbf{2 - 5}$ & $\mathbf{5 - 1 0}$ & $\mathbf{1 0 - 2 0}$ & $\mathbf{2 0 - 3 0}$ & $\mathbf{3 0}-\mathbf{5 0}$ & $\mathbf{5 0 - 1 0 0}$ & $\geq \mathbf{1 0 0}$ \\
\hline $\begin{array}{l}\text { Italy } \\
\text { Open field }\end{array}$ & & & & & & & & & \\
No. & 91,527 & 39,711 & 42,847 & 22,595 & 14,513 & 9627 & 2784 & 1424 \\
Area & 13,379 & 12,619 & 25,537 & 26,042 & 29,736 & 41,749 & 26,638 & 28,389 \\
GM & 0 & 0 & 0 & 122 & 2701 & 11,280 & 12,199 & 17,097 \\
Market gardening & & & & & & & \\
No. & 14,966 & 5,906 & 6258 & 3316 & 1917 & 1148 & 300 & 157 \\
Area & 2613 & 2645 & 5476 & 5285 & 4986 & 5371 & 2911 & 3446 \\
GM & 0 & 0 & 0 & 229 & 720 & 1553 & 1342 & 2132 \\
GM total & 0 & 0 & 0 & 351 & 3421 & 12,833 & 13,541 & 19,229 \\
\hline \multicolumn{7}{l}{ Source: Instituto Nacional de Estadística (www.ine.es); Italian National Institute of Statistics (www.istat.it). }
\end{tabular}

Based on these assumptions and the data given in Table 4 it is possible to calculate the area available for GM vegetables as a function of the minimum distance requirement (Figure 1). In both countries the current area of vegetable production is slightly less than $2500 \mathrm{~km}^{2}$.

Figure 1. Area available $\left(\mathrm{km}^{2}\right)$ for GM vegetables in Italy and Spain as a function of minimum distance requirements.

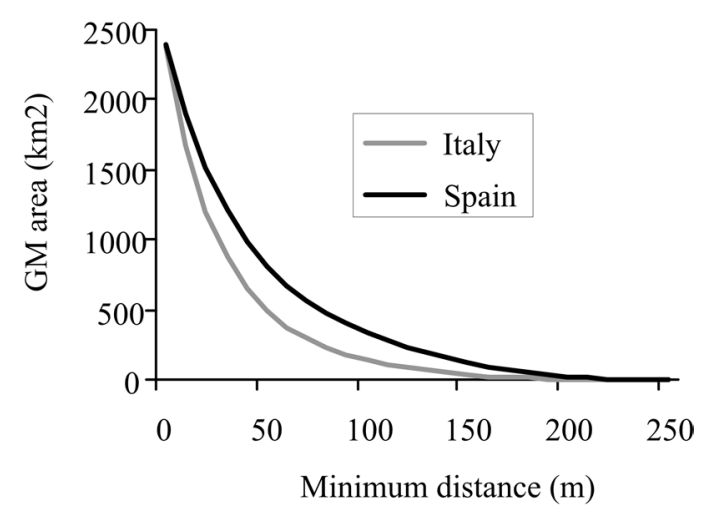

\section{Net Benefits of Biological Containment}

Combining the results of our technical and economic review in Sections 2 and 3, in this section we use this information in a cost-benefit framework. This framework is based on Beckmann and Wesseler [16] who assess how regulation and spatial aspects affect coexistence of GM and conventional crops. Formally, the main condition for coexistence of crops in a certain region is:

$$
V C=\sum_{i \in N} v_{N_{i}}+\sum_{i \in G} v_{G_{i}}-\sum_{i \in N} d_{i}-\sum_{i \in G} f_{i}>V_{N}, V_{G}
$$

Where $V C$ is the value of coexistence, $N$ is the set of conventional (non-GM) farmers and $G$ is the set of GM farmers. Variables $v_{N_{i}}$ and $v_{G_{i}}$ denote the value of non-GM and GM farming to farm $i$. Finally, $d_{i}$ denotes economic damage costs due to mixing (only incurred by non-GM farmers as they will incur a price loss) and $f_{i}$ denotes costs of measures implemented by GM farmers. Both economic damage costs and costs of measures implemented by GM farmers will obviously depend on the spatial 
distribution of both types of farms and on the possibility of cross pollination, as discussed above. $V C$ needs to outweigh both the value of $V_{N}$ (all farmers grow non-GM) and $V_{G}$ (all farmers grow GM) for coexistence to be profitable in the region under investigation. For a more detailed analysis coexistence costs see [1].

Equation (2) also indicates that coexistence is profitable only if the value of switching to GM crops is sufficiently large to cover the costs due to damage and preventive measures. Based on the information provided in Sections 2 and 3, we can make the following observations in light of Equation (2). First, the value of switching to GM tomato or eggplant is high relative to other crops, which implies that it is likely that $V_{G}$ outweighs $V_{N}$, when damage and costs are ignored. Second, the damage variables $d_{i}$ are zero, given the negligible probabilities of cross pollination for tomato and eggplant. Third, given the regulations in place in Italy and Spain, the costs of minimum distance requirements $f_{i}$ are likely to be borne by the GM farmers, as is already indicated in Equation (2). From these observations, it follows that the possibility of coexistence and the adoption rate of GM tomato and eggplant can be reduced to a trade-off between the value of switching to GM-crops (in the order of $€ 271-€ 5,063$ per ha) vs. the costs of minimum distance requirements, which depends on the spatial characteristics of farms and GM adoption (e.g., farm size, heterogeneity, plot sizes, farm density).

Our analysis in Section 3.2 suggests that only $21 \%$ and $34 \%$ of existing vegetable production land can be used for GM vegetables in Italy and Spain, respectively. Assuming that these numbers apply to both tomatoes and eggplants, this implies that at most 24,601 ha and 18,368 ha of GM tomatoes will be planted in Italy and Spain, respectively, and 2502 ha and 1446 ha of eggplant. These calculations assume that the buffer areas will be planted with non-GM crops, which serve as refuges to avoid pest resistance, and which will be processed and traded as GM crops because of the likely presence of GM genetic material. The benefits of biological containment will lie mainly in not having to keep a safe distance from other crops, and hence being able to use the entire tomato and eggplant growing area for GM crops. Given the aforementioned benefits of GM tomatoes and eggplants, making these buffer areas available for these crops amounts to $€ 25 \mathrm{mil}$ and $€ 42$ mil for tomatoes in Italy and Spain, respectively, and $€ 15$ mil and $€ 14$ mil for eggplants.

\section{Conclusions}

In this paper we assess the benefits and costs of introducing biologically contained GM crops, with an application to the potential introduction of GM tomatoes and eggplants in Italy and Spain. The main benefits of GM tomatoes and eggplants appear to lie in virus resistance and insect resistance, whereas the benefits of biological containment will probably lie in the ability to use the entire potential production area of the two crops.

Due to the available information, we assumed crops can be made resistant against all relevant viruses at once following the current trend of stacked GM crops (i.e., GM crops with multiple individual GM traits, such as specific insect resistance and herbicide tolerance). Hence, we ignored the possibility that, say, YLCV-resistant tomatoes can still become infected by CMV. The potential area of GM crops may be lower than calculated in this study as farmers may prefer non-GM crops for personal or commercial considerations. The minimum distance may have been chosen rather arbitrarily, although we believe it is a reasonable assessment given the fact that both crops are selfing species and 
distances used for crops with a similar reproductive biology (sugar beets and potato). The impact of minimum distance requirements on the potential area of GM crop, and hence the benefits of biological containment, may be smaller than we calculate because it is unlikely that all GM crops have a non-GM neighbor. Indeed, this assumption is somewhat inconsistent as there would be no coexistence problem in the first place if all tomatoes and eggplants were transgenic. Nevertheless, we believe this assumption was necessary to avoid any arbitrarily chosen proportion of GM and non-GM crops. On the other hand, the benefits of biological containment may be larger than we calculate because we assumed rather favorable parcellations. In reality, farms are likely to have several plots, and the plots are likely more rectangular or irregularly shaped than we assume. Therefore, farms probably have a larger border-area ratio than we assume, and hence suffer a more severe impact from distance measures. Nevertheless, a response might be clustering of farms [55]. Further, price effects caused by an increase in supply have not been considered. Prices for vegetables are very erratic. Nevertheless, using prices for 2005 is a safe assumption considering the recent increase in consumer prices for vegetables in the EU.

Given these limitations, our results show that the potential benefits of GM tomato and eggplant are considerable. Our calculations only include the direct benefits and costs. The indirect benefits caused by reduced pesticide use further increase the social benefits and contributes to improving the sustainability of agricultural production. The benefits of biological containment may be in the order of magnitude of up to $€ 42 \mathrm{mil}$, which is also a considerable amount depending on the minimum distance requirement. In particular smaller vegetable farmers, the majority of tomato and eggplant producers, would benefit. Even if prices for tomatoes and eggplants would decrease by $50 \%$ an amount of about $€ 20 \mathrm{mil}$ is considerable. Future research should consider supply and demand side effects and regional aspects in more detail such as the potential for reviving tomato production in the South of Italy. Our study provides a first step in that direction.

\section{Acknowledgements}

This study was financed by the European Union through the TRANSCONTAINER project.

\section{References and Notes}

1. Beckmann, V.; Soregaroli, C.; Wesseler, J. Coexistence of Genetically Modified (GM) and Non-Modified (non GM) Crops: Are the Two Main Property Rights Regimes Equivalent with Respect to the Coexistence Value? In Genetically Modified Food and Global Welfare, 1st ed.; Carter, C., Moschini, G.C., Sheldon, I., Eds.; Emerald Group Publishing: Bingley, UK, 2011.

2. National Research Council. The Impact of Genetically Engineered Crops on Farm Sustainability in the United States; The National Academies Press: Washington, DC, USA, 2010.

3. Kobayashi, K.; Munemura, I.; Hinata, K.; Yamamura, S. Bisexual sterility conferred by the differential expression of Barnase and Barstar: A simple and efficient method of transgene containment. Plant Cell Rep. 2006, 25, 1347-1354.

4. Kausch, A.P.; Hague, J.; Oliver, M.; Li, Y.; Daniell, H.; Mascia, P.; Watrud, L.S.; Stewart, C.N. Transgenic perennial biofuel feedstocks and strategies for bioconfinement. Biofuels 2010, 1, 163-176. 
5. Beckmann, V.; Soregaroli, C.; Wesseler, J. Coexistence rules and regulations in the European Union. Am. J. Agric. Econ. 2006, 88, 1193-1199.

6. Gómez-Barbero, M.; Berbel, J.; Rodríguez-Cerezo, E. Bt corn in Spain-the performance of the EU's first GM crop. Nat. Biotechnol. 2008, 26, 384-386.

7. Demont, M.; Daems, W.; Dillen, K.; Mathijs, E.; Sausse, C.; Tollens, E. Regulating coexistence in Europe: Beware of the domino-effect! Ecol. Econ. 2008, 64, 683-689.

8. Demont, M.; Dillen, K.; Daems, W.; Sausse, C.; Tollens, E.; Mathijs, E. On the proportionality of EU spatial ex ante coexistence regulations. Food Policy 2009, 34, 508-519.

9. Soregaroli, C.; Wesseler, J. Minimum Distance Requirements and Liability: Implications for Coexistence. In Environmental Costs and Benefits of Transgenic Crops, Wesseler, J., Ed.; Springer: Dordrecht, The Netherlands, 2005; pp. 165-182.

10. Skevas, T.; Fevereiro, P.; Wesseler, J. Coexistence regulations and agriculture production: The case of Bt maize production in Portugal. Ecol. Econ. 2010, 69, 2402-2408.

11. Wesseler, J.; Scatasta, S.; Fall, E.H. Environmental Benefits and Costs of GM Crops. In Genetically Modified Food and Global Welfare, 1st ed.; Carter, C., Moschini, G.C., Sheldon, I., Eds.; Emerald Group Publishing: Bingley, UK, 2011.

12. Moschini, G. Biotechnology and the development of food markets: retrospect and prospects. Eur. Rev. Agric. Econ. 2008, 35, 331-355.

13. Desquilbet, M.; Bullock, D.S. On the proportionality of EU spatial ex ante coexistence regulations: A comment. Food Policy 2010, 35, 87-90.

14. Devos, Y.; Demont, M.; Dillen, K.; Reheul, D.; Kaiser, M.; Sanvido, O. Coexistence of genetically modified (GM) and non-GM crops in the European Union: A review. Agron. Sustain. Dev. 2009, 29, 11-30.

15. Munro, A. The spatial impact of genetically modified crops. Ecol. Econ. 2008, 67, 658-666.

16. Beckmann, V.; Wesseler, J. Spatial Dimension of Externalities and the Coase Theorem: Implications for Coexistence of Transgenic Crops. In Regional Externalities; Heijman, W., Ed.; Springer: Berlin, Germany, 2007; pp. 215-234.

17. Accotto, G.P.; Nervo, G.; Acciarri, N.; Tavella, L.; Vecchiati, M.; Schiavi, M.; Mason, G.; Vaira, A.M. Field evaluation of tomato hybrids engineered with Tomato spotted wilt virus sequences for virus resistance, agronomic performance, and pollen-mediated transgene flow. Phytopathology 2005, 95, 800-807.

18. Miraglia, M.; Berdal, K.G.; Brera, C.; Corbisier, P.; Holst Jensen, A.; Kok, E.J.; Marvin, H.J.P.; Schimmel, H.; Rentsch, J.; Van Rie, J.P.P.F.; Zagon, J. Detection and traceability of genetically modified organisms in the food production chain. Food Chem. Toxicol. 2004, 42, 1157-1180.

19. Ilardi, V.; Barba, M. Assessment of functional transgene flow in tomato fields. Mol. Breed. 2001, 8, 311-315.

20. Sambandam, C.N. Natural cross pollination in eggplant (Solarium melongena). Econ. Bot. 1964, $18,128-131$.

21. Choudhary, B.; Gaur, K. The Development and Regulation of $\underline{B t}$ Brinjal in India (Eggplant/Aubergine); ISAAA: Ithaca, NY, USA, 2008.

22. Franceschetti, U.; Lepori, G. Natural cross pollination in eggplant. Sementi Elette 1985, 31, 25-28. 
23. Commission of the European Communities. Implementation of National Measures on the Coexistence of GM Crops with Conventional and Organic Farming; Commission of the European Communities: Brussels, Belgium, 2009.

24. FAO. FAOStat Database; Food and Agriculture Organization of the United Nations: Rome, Italy, 2007; Available online: http://faostat.fao.org (accessed on 7 October 2008).

25. Hsieh, T.H.; Lee, J.T.; Charng, Y.Y.; Chan, M.T. Tomato plants ectopically expressing Arabidopsis CBF1 show enhanced resistance to water deficit stress. Plant Physiol. 2002, 130, 618-626.

26. Martelli, G.P. Transgenic resistance to plant pathogens: benefits and risks. J. Plant Pathol. 2001, 83, 37-46.

27. Gallitelli, D. Present Status of Controlling Cucumber Mosaic Virus. In Plant Virus Disease Control; Hadidi, A., Khetarpal, R.H., Koganezawa, H., Eds.; American Phytopathological Society Press: St. Paul, MN, USA, 1998; pp. 507-523.

28. Tomassoli, L.; Ilardi, V.; Barba, M.; Kaniewski, W. Resistance of transgenic tomato to cucumber mosaic cucumovirus under field conditions. Mol. Breed. 1999, 5, 121-130.

29. Gianessi, L.; Sankula, S.; Reigner, N. Plant Biotechnology: Potential Impact for Improving Pest Management in European Agriculture-Tomato-Virus-Resistant Case Study; National Center for Food and Agricultural Policy: Washington, DC, USA, 2003.

30. Hayenga, M.; Thompson, L.C.; Chase, C.; Kaaria, S. Economic and environmental implications of herbicide-tolerant corn and processing tomatoes. J. Soil Water Conserv. 1992, 47, 411-417.

31. Rotino, G.; Acciarri, N.; Sabatini, E.; Mennella, G.; Lo Scalzo, R.; Maestrelli, A.; Molesini, B.; Pandolfini, T.; Scalzo, J.; Mezzetti, B.; Spena, A. Open field trial of genetically modified parthenocarpic tomato: seedlessness and fruit quality. BMC Biotechnol. 2005, 5, 32.

32. Dartt, B.; Black, R.; Marks, P.; Morrone, V. Costs of Processing Tomato Production in Monroe County, Michigan; Michigan State University: East Lansing, MI, USA, 2002.

33. Yardım, E.; Edwards, C. An economic comparison of pesticide application regimes for processing tomatoes. Phytoparasitica 2003, 31, 51-60.

34. Tatlidil, F.F.; Aktürk, D. Comparative analysis of contract and non-contract farming model in tomato production. J. Agron. 2004, 3, 305-310.

35. Engindeniz, S. Economic analysis of pesticide use on processing tomato growing: A case study for Turkey. Crop Prot. 2006, 25, 534-541.

36. Esengun, K.; Erdal, G.; Gündüz, O.; Erdal, H. An economic analysis and energy use in stake-tomato production in Tokat province of Turkey. Renew. Energy 2007, 32, 1873-1881.

37. Miyao, G.; Klonsky, K.M.; Livingston, P. Sample Costs to Produce Processing Tomatoes Direct Seeded in the Sacramento Valley; University of California, Davis: Davis, CA, USA, 2007.

38. Miyao, G.; Klonsky, K.M.; Livingston, P. Sample Costs to Produce Processing Tomatoes Transplanted in the Sacramento Valley; University of California, Davis: Davis, CA, USA, 2008. 
39. Marra, M.; Piggott, N. The Value of Non Pecuniary Characteristics of Crop Biotechnologies: A New Look at the Evidence. In Regulating Agricultural Biotechnology: Economics and Policy; Just, J.E., Alston, J.M., Zilberman, D., Eds.; Springer-Verlag: New York, NY, USA, 2006; pp. 145-178.

40. Brookes, G.; Barfoot, P. Global impact of biotech crops: Income and production effects, 1996-2007. AgBioForum 2009, 12, 184-208.

41. Qaim, M. The Economics of Genetically Modified Crops. Ann. Rev. Resour. Econ. 2009, 1, 665-694.

42. Donzella, G.; Spena, A.; Rotino, G.L. Transgenic parthenocarpic eggplants: Superior germplasm for increased winter production. Mol. Breed. 2000, 6, 79-86.

43. Acciarri, N.; Restaino, F.; Vitelli, G.; Perrone, D.; Zottini, M.; Pandolfini, T.; Spena, A.; Rotino, G. Genetically modified parthenocarpic eggplants: Improved fruit productivity under both greenhouse and open field cultivation. BMC Biotechnol. 2002, 2, 4.

44. Krishna, V.V.; Qaim, M. Potential impacts of Bt eggplant on economic surplus and farmers' health in India. Agric. Econ. 2008, 38, 167-180.

45. Goggin, F.L.; Jia, L.; Shah, G.; Hebert, S.; Williamson, V.M.; Ullman, D.E. Heterologous expression of the Mi-1.2 gene from tomato confers resistance against nematodes but not aphids in eggplant. Mol. Plant-Microbe Interact. 2006, 19, 383-388.

46. Kolady, D.E.; Lesser, W. Is genetically engineered technology a good alternative to pesticide use: The case of GE eggplant in India. Int. J. Biotechnol. 2008, 10, 132-147.

47. Gianessi, L.P.; Silvers, C.S.; Sankula, S.; Carpenter, J.E. Plant Biotechnology: Current and Potential Impact for Improving Pest Management in U.S. Agriculture an Analysis of 40 Case Studies-Insect Resistant Eggplant; National Center for Food and Agricultural Policy: Washington, DC, USA, 2002.

48. Molinar, R.H.; Yang, M.; Klonsky, K.M.; De Moura, R.L. Sample Costs to Produce Oriental Eggplant; University of California, Davis: Davis, CA, USA, 2005.

49. Molinar, R.H.; Yang, M.; Klonsky, K.M.; De Moura, R.L. Sample Costs to Produce Eggplant: American Eggplant; University of California, Davis: Davis, CA, USA, 2005.

50. USDA Agricultural Exchange Rate Data Set. United States Department of Agriculture: Washington, DC, USA, 2010; Available online: http://www.ers.usda.gov/Data/ExchangeRates/ (accessed on 31 May 2010).

51. Commission of the European Communities. Commission recommendation of 23 July 2003 on guidelines for the development of national strategies and best practices to ensure the coexistence of genetically modfied crops with conventional and organic farming. Off. J. Eur. Communities 2003, L189, 36-47.

52. Gladis, T.; Hammer, K.; Dathe, H.H.; Pellmann, H. Insect pollination and isolation requirements in tomato collections (Lycopersicon esculentum Mill). Plant Genet. Resour. Newsl. 1996, 106, 16-19.

53. Beckmann, V.; Soregaroli, C.; Wesseler, J. Ex-ante regulation and ex-post liability under uncertainty and irreversibility: Governing the coexistence of GM crops. Economics 2010, 4, No.2010-9. 
54. Skevas, T.; Fevereiro, P.; Wesseler, J. Coping with ex ante regulations for planting Bt-MaizeThe Portuguese experience. AgBioForum 2009, 12, 60-69.

55. Consmüller, N.; Beckmann, V.; Schleyer, C. The role of coordination and cooperation in early adoption of GM crops: the case of Bt maize in Brandenburg, Germany. AgBioForum 2009, 12 , 47-59.

56. Devos, Y.; Reheul, D.; Thas, O.; De Clercq, E.M.; Cougnon, M.; Cordemans, K. Implementing isolation perimeters around genetically modified maize fields. Agron. Sustain. Dev. 2007, 27, 155-165.

(C) 2011 by the authors; licensee MDPI, Basel, Switzerland. This article is an open access article distributed under the terms and conditions of the Creative Commons Attribution license (http://creativecommons.org/licenses/by/3.0/). 